\title{
PRINCIPIO DE LEGALIDAD Y SEGURIDAD JURÍDICA EN LA OEDE. REFLEXIONES ACERCA DE LA STJUE DE 3 DE MARZO DE 2020 (ASUNTO VALTONYC)
}

\author{
Amparo Martínez Guerra*
}

\section{Consideraciones iniciales}

El día 3 de marzo de 2020, la Gran Sala del Tribunal de Justicia de la Unión Europea (TJUE) resolvió la cuestión prejudicial penal planteada por El Tribunal de Apelación de Gante (Bélgica) en el asunto C-717-18, conocido como asun-

Recibido: mayo 2020. Aceptado: mayo 2020

*Profesora Ayudante Doctora (acre.Titular).

Facultad de Derecho de la Universidad Complutense de Madrid. Ciudad Universitaria 28040, Madrid. Email: ampmarti@ucm.es.

Este trabajo ha sido realizado en el marco del proyecto ID Derecho Penal y distribución de la riqueza en la Sociedad Tecnológica (PID2019107074RB-I00 cuyo IP es Paz M. De la Cuesta Aguado, Universidad de Cantabria). Una parte de este trabajo fue presentada como comunicación en el 5th European Meeting on European Jurisprudence, celebrado el 15 de mayo de 2020 (modalidad online). Agradezco los comentarios realizados por el moderador del Webinar 19. Derecho Penal, el Profesor Lascuráin Sánchez (Catedrático de Derecho Penal UAM). 
to Valtonyc ${ }^{1}$. El fallo vino a confirmar la Opinión del Abogado General de la UE (Sr. Bobek) sobre el asunto emitida el 26 de noviembre de $2019^{2}$.

Las dos consultas realizadas por el Tribunal de Apelación de Gante al TJUE en la cuestión prejudicial pueden resumirse en una: a Loi relative au mandat d'arrêt européen, de 19 de diciembre de 2003 (Wet $E A B)^{3}$, transposición belga del art. 2.2 de la Decisión Marco 2002/578/JAI, del Consejo de 13 de junio $^{4}$ ¿debe tomar como base la ley penal del Estado emisor en el momento de emitir la Orden Europea de Detención y Entrega (OEDE) o aquélla en vigor en el momento de comisión del delito que dió lugar a la condena por el Tribunal nacional?.

\section{El procedimiento en el ámbito nacional}

La SAN 494/2017, de 21 de febrero ${ }^{5}$ condenó al Sr. Miguel Arenas Beltrán (conocido artísticamente como Valtonyc) por diversos delitos. En primer lugar, por un delito de enaltecimiento del terrorismo y humillación a las víctimas (art. $578 \mathrm{CP}$ ) a una pena de prisión de dos años e inhabilitación absoluta de ocho años (art. 579.2 CP). En segundo lugar, a una pena de séis meses de prisión por un delito de amenazas no condicionales contra el presidente del Círculo Balear (art. 169.2 CP). Finalmente, a una pena privativa de libertad de un año de prisión por un delito de calumnias e injurias a la Corona (art. 490. 3 CP).

1 STJUE (Gran Sala) de 3 de marzo de 2020 (Asunto C-717-18).

2 Opinión Abogado General Sr. Bobek, de 26 Noviembre de 2019, Asunto C-717-18, Procureur-generaal (Mandat d'arrêt européen - Double incrimination).

3 Loi relative au mandat d'arrêt européen, 19 Decembre, 2003, Belgisch Staatsblad de 22 de diciembre de 2003, p. 60075).

4 Decisión Marco 2002/584/JAI, de 13 de junio, relativa a la orden de detención europea y a los procedimientos de entrega entre Estados miembros, DOUE, L190 /1, de 18.07.2002.

5 SAN (Sección Segunda) 494/2017, de 21 de febrero. Ponente: Espejel Jorquera. 
Apenas un año después, la STS 79/2018, de 15 de febrero de $2018^{6}$ desestimó el recurso de casación interpuesto por la representación letrada del condenado contra ese fallo y confirmó en todos sus aspectos la sentencia de instancia. En su razonamiento, el Alto Tribunal venía a mantener que, con respecto a la conducta de exaltación del terrorismo y humillación a las víctimas, delito por el cual se pedía la entrega a los Tribunales Belgas, no cabía asumir la tesis del recurrente de que dicha conducta estuviese protegida por el derecho fundamental a la libertad de expresión.

Para llegar a la conclusión anterior, el Tribunal atendía a la valoración de la letra de las canciones del recurrente, publicadas en redes sociales o plataformas abiertas al público. Sin embargo, uno de los aspectos más llamativos del fallo del TS es la constante alusión a la doctrina del Tribunal Constitucional mantenida en su sentencia 177/2015, de 22 de julio (Stern Taullats y Roura Capellera). En primer lugar porque, como ya hiciera en ese asunto, tanto el Minsterio Público como la Abogacía General del Estado, mantuvieron la incitación al odio contra la institución Monárquica como elemento clave para rechazar el amparo constitucional de la libertad de expresión. En segundo lugar, porque el fallo del TEDH en ese asunto concretamente se produciría apenas un mes después, el 13 de marzo de ese mismo año ${ }^{7}$. En su resolución, TEDH estimó que se vulneraba el derecho a la libertad de expresión de los demandantes y que no podía sostenerse la justificación de los Tribunales españoles de que el discurso de los demandantes "exhortaba al odio y a la violencia contra el Rey y la Monarquía". Esta decisión no fue recurrida

6 STS (Sala Segunda) 79/2018, de 15 de febrero de 2018. Ponente Monterde Ferrer.

7 STEDH (Sección Tercera) Stern Taulats y Roura Capellera c. España $\left(\mathrm{n}^{\mathrm{o}}\right.$ 51168/15 y 51186/15) de 13 de marzo de 2018.

8 Véase al respecto, PRESNO LLINERA, M. A:“Crónica de una condena anunciada: el asunto Stern Taulats y Roura Capellera c. España sobre la quema de fotos del Rey, Revista UNED, Teoría y Realidad Constitucional, $\mathrm{n}^{\circ}$ 42, 2018, pp. 539-449. En relación a la ejecución de la decisión del TEDH y 
a la Gran Sala por el Estado español. Tras el fallo del TEDH en el asunto Stern Taulats y Roura Capellera la comunicación de la Abogacía General del Estado a la Secretaría del Comité de Ministros con respecto a la ejecución de la sentencia sí abrió la puerta a la posible adopción de algún otro tipo de medidas generales. Entre ellas se incluyó el desarrollo de un "programa de formación especializada en materia de delitos de odio para miembros de la Carrera Judicial y Fiscal, con especial atención a la jurisprudencia del TEDH y a su impacto en la interpretación del Derecho español"'.

A pesar de la reiteración de fallos condenatorios en la materia, el Legislador se ha resistido a implementar medidas que eviten futuras condenas por hechos similares. De manera clara y reiterada, el TEDH ha cuestionado la aplicación de los tipos penales de injurias, incluidas las cometidas contra la Corona, y calumnias contra esta institución también en fallos Otegui Mondragón c. España $(2011)^{10}$. La contundencia de los razonamientos del TEDH, no ha propiciado hasta ahora que las reformas del $\mathrm{CP}$ hayan contemplado una derogación de los tipos penales, como sí se hizo con la sección 36 de la Ley francesa de 1881, de Libertad de Prensa, tras el fallo Colombani c. Francia $(2002)^{11}$.

el recurso de revisión, véanse las observaciones de MARTÍNEZ GUERRA, A: "STEDH Otegui Mondragón c. España (2018) y la revisión penal. Voto particular de la magistrada Keller", Revista de Derecho y Proceso Penal, $\mathrm{n}^{\circ}$ 55, 2019, pp. 19-42.

9 Abogacía General del Estado, Action Plan (14/02/2019) Communication from Spain concerning the case of Stern Taulats and Roura Capellera v. Spain (Application No. 51168/15) p. 4, disponible en https://search.coe.int/ $\underline{\mathrm{cm} / \text { Pages/result details.aspx? ObjectId }=09000016809324 \mathrm{c} 9}$

10 Sobre la problemática de estos tipos penales y su evolución, vid. MARTÍNEZ GUERRA, A., "Lección 2. Delitos contra la Corona", en Álvarez García, F.J. Tratado de Derecho Penal español. Parte Especial. IV Delitos contra la Constitución, Valencia, Tirant lo blanch, 2015, pp. 118-130.

11 STEDH Colombani c. Francia $\left(n^{\circ} 51279\right)$ de 25 de junio de 2002, razonamiento reiterado en STEDH Eon c. Francia (n ${ }^{\circ}$ 26118/10), de 13 de marzo, con respecto a las injurias al Presidente de la República. 
El día 2 de abril de 2020, se publicó en el Boletín Oficial del Senado la Proposición de Ley por la que se modifica la Ley Orgánica 10/1995, de 23 de noviembre, del Código Penal, para despenalizar las injurias a la Corona y los ultrajes a España ${ }^{12}$. Con plazo suspendio a día de hoy, la iniciativa presentada por los Grupos Parlamentarios de Esquerra RepublicanaEuskal Herria-Bildu solicita la supresión de los arts. 490.3 (calumnias e injurias a la Corona en el ejercicio de las funciones) y 491 (calumnias e injurias a la Corona fuera del ejercicio de las funciones) y el art. 543 CP (ultrajes a España). En sus antecedentes se señalan expresamente los fallos aludidos del $\mathrm{TEDH}^{13}$.

Meses después de la inadmisión del recurso de casación por parte Tribunal Supremo, el 19 de abril de 2018, el Tribunal Constitucional desestimó mediante Providencia el recurso de amparo interpuesto por el recurrente. El órgano indamitió el recurso por falta de justificación de la especial transcendencia constitucional ${ }^{14}$. Por su parte, el 11 de julio de 2019, el TEDH inadmitió también el recurso del Sr. Arenas Beltrán en el que se solicitaba la nulidad de la orden de ingreso en prisión dictada por la AN.

Todos los delitos fueron cometidos por el Sr. Arenas Beltrán en 2012 y 2013 y se juzgaron conforme a la ley penal vigente en el momento de comisión de los hechos. La redacción del tipo penal del entonces el art. $578 \mathrm{CP}$ establecía una pena máxima de 2 años de prisión. Este tipo penal, introducido por

12 Proposición de Ley por la que se modifica la Ley Orgánica 10/1995, de 23 de noviembre, del Código Penal, para despenalizar las injurias a la Corona y los ultrajes a España, Boletín Oficial de las Cortes Generales, Senado, XIV legisltura, 2 de abril de 20202, nº 37, p. 2.

13 Los mismos hechos y fallos se establecen en la Exposición de Motivos de la Iniciativa dirigida a la Mesa del Senado, con fecha de 24.03.2020 y presentada por las Senadoras Castel i Fort, Cortés Gès y el Senador Elejabarrieta Díez.

14 Providencia del TC 1242/2018, de 19 de abril. 
el artículo noveno de la LO 7/2000, de 22 de diciembre venía a castigar "el enaltecimiento o la justificación por cualquier medio de expresión pública o difusión de los delitos comprendidos en los artículos 571 a 577 de este Código o de quienes hayan participado en su ejecución, o la realización de actos que entrañen descrédito, menosprecio o humillación de las víctimas de los delitos terroristas o de sus familiares se castigará con la pena de prisión de uno a dos años". ${ }^{15}$ La Exposición de Motivos de la Ley justificaba la incorporación de esta nueva conducta al Código Penal por el refuerzo y apoyo a situaciones criminales muy graves y a la sostenibilidad y perdurabilidad de las mismas, pero también como otra "manifestación muy notoria de cómo por diversas vías generará el terror colectivo para hacer avanzar los fines terroristas".

El Legislador español señalaba que no se trataba de "prohibir el elogio o la defensa de ideas o doctrinas, por más que éstas se alejen o incluso pongan en cuestión el marco constitucional, ni, menos aún, prohibir la expresión de opiniones subjetivas sobre acontecimientos históricos o de actualidad. Por el contrario, se trata de algo tan sencillo como perseguir la exaltación de los métodos terroristas, radicalmente ilegítimos desde cualquier perspectiva constitucional, o de los autores de estos delitos, así como las conductas especialmente perversas de quienes calumnian o humillan a las víctimas al tiempo que incrementan el horror de sus familiares. Actos todos ellos que producen perplejidad e indignación en la sociedad y que merecen un claro reproche penal" ${ }^{\prime 16}$. El posible conflicto con el ejercicio de la libertad de expresión estaba presente en la propia justificación de la reforma, como lo estaría en los textos adoptados en el ámbito del Consejo de Europa y de la Unión Europea posteriormente.

15 LO 7/2000, de 22 de diciembre, de modificación de la Ley Orgánica 1071995, de 23 de noviembre, del Código Penal y de la Ley reguladora de la Responsabilidad de los Menores en relación con los delitos de terrorismo, BOE núm. 307 de 23 de diciembre de 2000.

16 LO 7/2000, de 22 de diciembre, Exposición de Motivos, apartado III. 
El art. 5.1 del Convenio del Consejo de Europa para la prevención del terrorismo, de 16 de mayo de 2005 (Convenio de Varsovia $)^{17}$ define, a los efectos del Convenio, los elementos del tipo penal de provocación pública para cometer delitos terroristas. Entiende por tales la "difusión o cualquier otra forma de puesta a disposición del público de mensajes con la intención de incitar a cometer delitos terroristas cuando ese comportamiento, ya preconice directamente o no la comsiión de delitos terroristas, cree peligro de que se puedan cometer uno o varios delitos". El segundo apartado de este precepto, establece la obligación de los Estados Parte de tipificar esta conducta cuando se cometa ilegal o intencionadamente. La complejidad interpretativa de los términos utilizados por el Convenio trata de paliarse en su Informe Explicativo ${ }^{18}$. Tanto en su Preámbulo (apartado 44) como en los parágrafos 86 a 105 del Informe, se pone de manifiesto la fina línea divisoria entre la criminalización de la conducta y la posible afectación de los principios de libertad de expresión y asociación. Por su parte, en el ámbito de la Unión Europea, la Decisión Marco 2008/919/JAI, del Consejo, de 28 de noviembre, por la que se modifica la Decisión Marco del Consejo de Europa, de 13 de junio de 2002, sobre la lucha contra el terrorismo ${ }^{19}$, viene a mostrar la misma preocupación en su Considerando número 14. En él afirma con rotundidad que "la expresión pública de opiniones radicales, polémicas o controvertidas sobre cuestiones políticas sensibles, incluido el terrorismo, queda fuera del ámbito de la presente Decisión marco $y$, en especial, de la definición de provocación a la comisión de delitos de terrorismo". El propio art. 2 de la Decisión Marco de 2008 delimita expresamente el alcance de las previsiones pena-

17 Instrumento de Ratificación del Convenio del Consejo de Europa para la Prevención del Terrorismo (Convenio 196 del Cosnejo de Europa) hecho en Varsovia el 16 de mayo de 2005, BOE. 250, de 16 de octubre de 2009.

18 Council of Europe. Explanatory report to the Council of Europe Convention to the prevention of Terrorism (ECTS, $\mathrm{n}$. 196), Warsaw, de 16 de mayo de 2005.

19 DOUE, L 330/21, de 9 de diciembre de 2008 y DOUE, L 164/3, de 22 de junio de 2002, respectivamente. 
les, estableciendo como garantía infranqueable las tradiciones constitucionales. Ello incluye las garantías procesales, en el ámbito de la libertad de prensa y expresión también de los medidos de comunicación.

La Ley Orgánica 2/2015, de 30 de marzo, por la que se modifica la Ley Orgánica 10/1995, de 23 de noviembre, del Código Penal, justifica su razón de ser precisamente en la Decisión Marco de 2008 y otros instrumentos de naturaleza internacional que se aprueba como respuesta al incremento de acciones terroristas de corte yihadista. La reforma elevó la pena máxima de los delitos contenidos en los arts. 578 y 579 CP de los dos a los tres años de prisión ${ }^{20}$. La aprobación de esta Ley no sólo afectó a la configuración de los delitos de terrorismo contenidos en el Capítulo VII del Título XXII del CP, sino también la jurisdicción de los Tribunales españoles para perseguirlos. La tramitación de la reforma fue polémica, entre otras razones porque se optó por el procedimiento exprés de la Proposición de Ley Orgánica (PPLO), evitando así los informes preceptivos del Consejo General del Poder Judicial, del Consejo Fiscal y del Consejo de Estado $^{21}$.

La Exposición de Motivos de la LO 2/2015 coincidía sustancialmente con el de la PPLO presentada por los Grupos Parlamentarios Popular (GPP), Socialista

20 Sobre la evolución de la art. 578, vid. BERNAL CASTILLO, J., "El enaltecimento del terrorismo y la humillación a sus víctimas como formas del "discurso del odio", Revista de Derecho Penal y Criminología, $3^{\mathrm{a}}$ época, núm. 16, de julio de 2016, pp. 13-44.

21 Desde el punto de vista de su persecución, la LO 2/2015, de 30 de junio, vino a modificar el art. 23. 4 LOPJ en materia delitos de terrorismo, reconociendo de forma implícita, el recorte que llevó a cabo la $L O 1 / 2014$, de 13 de marzo, de modificación de la LO 6/1985, de 1 de julio, del Poder Judicial, relativa a la justicia universal. El resultado final de esa reforma de naturaleza procesal fue la creación de otro régimen más de persecución ad hoc en el art. 23.4 LOPJ. La simple estancia del autor en territorio español o su contacto o colaboración con un español o extranjero que resida o se encuentre en España es principio de atribución de la jurisdicción a los Tribunales españoles (Disposición final primera LO 2/2015, de 30 de marzo). 
(GPS) y Grupo Mixto $(\mathrm{GMx})^{22}$. En ella se aludía al contenido y obligaciones generales impuestas por las Resoluciones del Consejo de Seguridad de Naciones Unidas 2178 (2014) de 24 de septiembre ${ }^{23}$ y 1373 (2001) de 28 de septiembre ${ }^{24}$. La primera conminaba a los Estados para que "se cercioren de que sus leyes $y$ otros instrumentos legislativos internos tipifiquen delitos graves que sean suficientes para que se pueda enjuiciar y sancionar las conductas terroristas que se describen, de tal forma que quede debidamente reflejada la gravedad del delito". La segunda reconocía "la necesidad de que los Estados complementen la cooperación internacional adoptando otras medidas para prevenir y reprimir en sus territorios, por todos los medios legales, la financiación y preparación de esos actos de terrorismo". Ambas resoluciones remiten de forma explícita a las obligaciones impuestas por el Convenio Internacional para la represión y la financiación del terrorismo (1999) ${ }^{25}$. La primera de ellas mostraba además una clara preocupación por el reclutamiento de combatientes extranjeros y por la amenaza que suponía para los países de origen, destino y tránsito ${ }^{26}$.

22 Proposición de Ley Orgánica por la que se modifica la Ley Orgánica 10/1995, de 23 de noviembre, del Código Penal, en materia de delitos de terrorismo, Boletín Oficial de las Cortes Generales, Congreso de los Diputados, X Legislatura, Serie B: Proposiciones de Ley Núm. 211-1, 122/000189, pp. 1-8.

$23 \mathrm{~S} / \mathrm{RES} / 2178$ (2014).

24 S/RES/1373 (2001).

25 Instrumento de ratificación del Convenio Internacional para la represión y la financiación del terrorismo, hecho en Nueva York el 9 de diciembre de 1999 (BOE núm. 123, de 23 de mayo de 2002).

26 "Expresando grave preocupación por la grave y creciente amenaza que plantean los combatientes terroristas extranjeros, a saber, las personas que viajan a un Estado distinto de su Estado de residencia o nacionalidad con el propósito de cometer, planificar o preparar actos terroristas o participar en ellos, o de proporcionar o recibir adiestramiento con fines de 
La problemática descrita con respecto a la posible comisión de delitos de exaltación del terrorismo y el ejercicio legítimo de la libertad de expresión se ha puesto de manifiesto recientemente en la sentencia del Pleno del TC 35/2020, de 25 de febrero ${ }^{27}$. El fallo ha anulado la STS 4/2017, de 18 de enero ${ }^{28}$, que condenó al cantante César Montana (conocido artísticamente como César Strawberry) líder del grupo Def con Dos a un año y seis meses de prisión y una pena de 6 meses inhabilitación absoluta por delito de enaltecimiento del terrorismo. La sentencia del TS, con el voto particular del Magistrado Andrés Ibáñez, resolvió el recurso de casación interpuesto por el Ministerio Fiscal contra la SAN 20/2016, de 18 de julio, que absolvió al acusado de dicho delito al entender que "con los mensajes buscara defender los postulados de la organización terrorista ni humillar ni despreciar a las víctimas" ${ }^{29}$. Por su parte, el TC considera que el tipo penal sí que requiere entrar a valorar cuál es la finalidad de las afirmaciones realizadas por el recurrente. No puede, por tanto aceptarse sin más que resulte irrelevante "ponderar cuál era la intención- irónica, provocadora, sarcástica-del recurrente al emitir sus mensajes en relación con su trayectoria profesional como artista y personaje influyente en el contexto en el que se emitían los mensajes y con el mantenimiento de una línea de coherencia personal de condena de la violencia como medio de solución de conflictos". Y continúa aclarando que "No corresponde a nuestra jurisdicción pronunciarnos sobre la intención perseguida con los mensajes enjuiciados se integra como elemento del tipo objetivo de acusación. Ahora bien, desde la perspectiva

terrorismo, incluso en relación con conflictos armados....Expresando grave preocupación por quienes intentan viajar para convertirse en combatientes terroristas extranjeros... expresando preocupación porque los terroristas $y$ las entidades terroristas han establecido redes internacionales entre los Estados de origen, tránsito y destino, a través de las cuales se mueven en una y otra dirección los combatientes terroristas extranjeros y los recursos para apoyarlos".

27 STC (Pleno) 35/2020, de 25 de febrero. Ponente Xiol Ríos.

28 STS 4/2017, de 18 de enero. Ponente Marchena Gómez.

29 SAN $\left(\right.$ Secc. $\left.1^{\circ}\right)$ 20/2016, de 18 de julio. Ponente Fernández Prado. 
de la exigencia constitucional de ponderar previamente la eventual concurrencia de una conducta susceptible de ser integrada en el ámbito del derecho fundamental a la libertad de expresión, aquella intención, en ausencia de otros factores que puedan ser reveladores respecto de los restantes elementos a que se ha hecho referencia, lejos de de constituir una falacia resulta ser uno de los aspectos indispensables en el análisis, pues su preterición en tales circunstancias hace definitivamente imposible ponderar si el acto comunicativo debe entenderse como realizado en el ejercicio legítimo de aquel derecho".

Con independencia de las cuestiones de naturaleza en materia de cooperación jurídica internacional que se expondrán a continuación y que constituyen el objeto de la cuestión prejudical ante el TJUE, quedaría abierto el examen de la extralimitación del Sr. Arenas Beltrán en el ejercicio de la libertad de expresión. La desestimación del recurso de amparo por parte del TC abrió la puerta a la presentación de la demanda ante el TEDH al haber agotado la vía interna.

\section{Problemática de la entrega: actuaciones y planteamiento de la cuestión prejudicial}

El 25 de mayo 2018 la AN española emitió una primera OEDE para la que los Tribunales Belgas entregaran al Sr. Arenas Beltrán a efectos de ejecución de la pena. El Tribunal de Primera Instancia de Flandes Oriental (Seción Gante) solicitó información adicional para decidir sobre la ejecución. El 27 de junio de 2018, la AN emitió una segunda OEDE en la que, además de la descripción detallada de las infracciones cometidas ${ }^{30}$, se incluían los textos de las canciones de rap y se completaba el recuadro f) del Anexo (información facultativa sobre otras circunstancias relacionadas con el caso), incluyendo en las referencias a los arts. 578 y 579 CP en su versión modificada en 2015 .

30 Recuadro e) del Anexo de la Decisión Marco 2002/584/JAI de 13 de junio, relativa a la orden de detención europea y a los procedimientos de entrega entre Estados Miembros, DOUE, L 190/1, de 18 de julio de 2002. 
Según consta en el relato de la propia sentencia del TJUE, ese apartado f) se había dejado en blanco en la primera OEDE. Ante la petición de aclaración por parte del Tribunal Belga, la AN "remitió información complementaria relativa al régimen de penas" e indicó que la "referencia en la segunda orden de detención europea a las disposiciones del Código Penal en su versión de 2015 era un error" (STJUE de 3 de marzo de 2020, apartado 13).

El Tribunal de Primera Instancia de Flandes Oriental (Sección Gante), mediante auto de 17 de septiembre de 2018, denegó la ejecución de la OEDE por dos razones. La primera porque entendía que el delito de enaltecimiento del terrorismo y humillación a las víctimas no podía ser considerado un delito de "terrorismo" a los efectos del art. 2.2 de la Decisión Marco 2002/584/JAI, de 13 de junio. Según el Tribunal debía atenderse al artículo 578 del Código Penal español en la versión vigente en la fecha en que se cometieron los hechos del litigio principal, castigados entonces con una pena máxima de 2 años. La segunda, porque no cumplía el requisito de la doble incriminación por todos los delitos incluidos en la OEDE emitida por la AN.

Contra ese auto de denegación, el Ministerio Fiscal Belga interpuso recurso ante el Tribunal de Apelación de Gante por entender que el delito de enaltecimiento y humillación a las víctimas sí que se encontraba contenido en el art. 5.2.2 de la WET $E A B$, de 19 de diciembre, ley belga de transposición de la Decisión Marco 2002/584/ JAI, de 13 de junio ${ }^{31}$. Ante ello, el Tribunal de Apelación planteó la cuestión prejudicial al TJUE para que determinase si debía atender a la redacción de la norma pe-

31 Loi relative au mandat d'arrêt européen, 19 Decembre, 2003. La transposición que realizó el Legislador belga es la siguiente: Art. 5. 1. L'exécution est refusée si le fait qui est à la base du mandat d'arrêt européen ne constitue pas une infraction au regard du droit belge.

§ 2. Le paragraphe précédent ne s'applique pas si le fait constitue une des infractions suivantes, pour autant qu'il soit puni dans l'Etat d'émission d'une peine privative de liberté d'un maximum d'au moins trois ans: $2^{\circ}$ terrorisme. 
nal en el momento de comisión de los hechos o, por el contrario, a la vigente en el momento de emisión de la OEDE. Esta última postura era la mantenida por los Gobiernos Español y Belga y por el Ministerio Fiscal Belga.

\section{Análisis de la cuestión prejudicial}

El contenido de la cuestión prejudicial privota en torno a las condiciones a las que se debe atender para eximir del control de doble incriminación establecido en el art. 2.2 de la Decisión Marco 2002/584/JAI, de 13 de junio de 2002. Conforme a este precepto, "darán lugar a la entrega, en virtud de una orden de detención europea, en las condiciones que establece la presente Decisión marco y sin control de la doble tipificación de los hechos, los delitos siguientes, siempre que estén castigados en el Estado miembro emisor con una pena o medida de seguridad privativas de libertad de un máximo de al menos 3 años, tal y como se definen en el Derecho del Estado emisor: terrorismo" (segundo delito de las treinta y dos categorías de la lista).

La cuestión planteada no resulta badalí. La disparidad de las penas entre la versión del precepto penal vigente en el momento de comisión de los hechos y aquélla en la que se emiten las dos órdenes europeas de detención determinaría el sometimiento o no al control de doble incriminación. Con respecto a esa dispensa del control de doble incriminación en determinados casos del art. 2.2 de la Decisión Marco 2002/584/JAI, el TJUE ya tuvo la oportunidad de pronunciarse con claridad en el asunto Advocaten Voor de Wereld, de 3 de mayo de $2007^{32}$. En esta sentencia, el órgano afirmó que la dispensa de la doble incriminación revista en la Decisión Marco no afectaba al principio de legalidad de los arts. 7 del CEDH (principio de legalidad) y jurisprudencia del TEDH derivada del mismo, y en los arts. 6 (derecho a la libertad y la seguridad) y 49.1 (principio de

32 STJUE (Gran Sala) Advocaten Voor de Wereld, de 3 de mayo de 2007 (C-303/05). 
legalidad y de proporcionalidad de los delitos y las penas) de la Carta de Derechos Fundamentales de la UE.

En su opinión de noviembre de 2019, el Abogado General del TJUE recordó que la dispensa del control de doble tipificación en determinados casos del art. 2.2 de la DM 2002/584/ JAI, de 13 de junio, no afecta al contenido del principio de legalidad. Sin embargo, de acuerdo con la jurisprudencia del TJUE el principio de seguridad jurídica exige además que dicho principio sea conciliable con las exigencias de claridad y previsibilidad en materia penal. Sólo de esta manera se garantiza el grado más alto de seguridad jurídica, que constituye la base de la confianza en el Estado emisor de ejecución. De ese grado de confianza depende el éxito de la Decisión Marco, instrumento que es la piedra angular de la cooperación judicial en materia penal en la UE. Una interpretación contraria, entiende el Abogado General, socavaría esos principios de previsibilidad y seguridad jurídica y obligaría al Estado de ejecución a comprobar los cambios posteriores en los Estados de emisión. Se debe, por tanto, atender a la pena señalada en el momento de comisión de los hechos, especialmente en este caso, donde nos encontramos con sentencia condenatoria.

La postura ha sido aceptada y ratificada por la Gran Sala del TJUE en su decisión de 3 de marzo de 2020. Ambas resoluciones recuerdan que la definición concreta de los delitos y las penas aplicables son fijadas por el Estado Miembro emisor, sin que ello vulnere el principio de legalidad. Así lo mantuvo el órgano en el asunto Advocaten Voor de Wereld (2007) ${ }^{33}$, decisión a la que se remite de manera recurrente en la resolución de esta cuestión prejudicial.

33 Con detalle sobre la importancia del asunto, véase, FUGLSANG SORENSEN, H., "Advocaten voor de Wereld: The salvation of mutual trust", en MITSILEGAS, V. / DI MARTINO, A. / MANCANO, L. (eds.) The Court of Justice and European Criminal Law. Leading cases in a contextual analysis, London, Hart Publishing, Modern Studies in European Law, 2019, pp. 333 347. 


\section{Reflexiones finales}

La sentencia de la Gran Sala del TJUE de 3 de marzo de 2020, que confirma la opinión del Abogado General de la UE de 26 de noviembre de 2019, obliga los órganos judiciales a grantizar los principios de claridad y previsibilidad de la norma penal como manifestación del principio de seguridad jurídica en el ámbito de la cooperación judical en materia penal. Sólo así se garantiza el más alto grado de seguridad jurídica, principio sobre el que descansa a su vez todo el sistema Europeo de Detención y Entrega.

La primera consecuencia del fallo del TJUE es ratificar la negativa de los Tribunales Belgas de entregar al ciudadado español a la Audiencia Nacional para la ejecución de la sentencia condenatoria. Desde el punto de vista Político Criminal, el fallo recuerda a los Legisladores nacionales la necesidad de analizar detenidamente las penas establecidas en las nuevas modalidades delictivas no expresamente previstas en las categorías consignadas en el art. 2.2 de la Decisión Marco 2002/584/JAI, de 13 de junio. Ese análisis debería ser especialmente cuidadoso en procesos de reformas penales que tengan o no su origen en la transposición de Directivas comunitarias.

El cambio apresurado, tardío y continuo de tipos penales o de algunos de sus aspectos incluida la pena, puede llevar a una descoordinación entre los instrumentos jurídico-penales sustantivos y procesales. Por ello, y con independencia que de la OEDE sea un intrumento de cooperación jurídica en materia penal, el principio de legalidad y, por tanto de seguridad jurídica que rige en el Derecho penal, debe hacerlo también cuando un Estado Miembro utiliza este instrumento de Derecho Comunitario y solicita la entrega de un sujeto para el cumplimiento de un pena privativa de libertad.

En el caso concreto que nos ocupa, esta sentencia del TJUE ha venido a recordarnos, como ya hiciera la Sentencia de la Gran Sala del TEDH en el asunto Inés del Río Prada c. España en 2013, que los límites, presupuestos y el alcance del principio de legalidad en materia penal son elemento irrenunciable de la seguridad jurídica y garantía de respeto del funcionamiento de la Administración de Justicia un Estado Democrático y de Derecho. 